University of Nebraska - Lincoln

DigitalCommons@University of Nebraska - Lincoln

Nutrition and Health Sciences -- Faculty

Publications

Nutrition and Health Sciences, Department of

2016

Carbohydrate Intake in Form of Gel Is Associated With Increased Gastrointestinal Distress but Not With Performance Differences Compared With Liquid Carbohydrate Ingestion During Simulated Long-Distance Triathlon

Mahdi Sareban

University of Ulm, m.sareban@salk.at

David Zügel

University of Ulm

Karsten Koehler

University of Nebraska - Lincoln, kkoehler3@unl.edu

Paul Hartveg

University of Ulm

Martina Zügel

University of Ulm

Sareban, Mahdi; Zügel, David; Koehler, Karsten; Hartveg, Paul; Zügel, Martina; Schumann, Uwe; Steinacker, Jürgen Michael; and Treff, Gunnar, "Carbohydrate Intake in Form of Gel Is Associated With Increased Gastrointestinal Distress but Not With Performance Differences Compared With Liquid Carbohydrate Ingestion During Simulated Long-Distance Triathlon" (2016). Nutrition and Health Sciences -- Faculty Publications. 82.

http://digitalcommons.unl.edu/nutritionfacpub/82

This Article is brought to you for free and open access by the Nutrition and Health Sciences, Department of at DigitalCommons@University of Nebraska - Lincoln. It has been accepted for inclusion in Nutrition and Health Sciences -- Faculty Publications by an authorized administrator of DigitalCommons@University of Nebraska - Lincoln. 
See next page for additional authors

Follow this and additional works at: http://digitalcommons.unl.edu/nutritionfacpub

Part of the Human and Clinical Nutrition Commons, Molecular, Genetic, and Biochemical Nutrition Commons, and the Other Nutrition Commons 
Authors

Mahdi Sareban, David Zügel, Karsten Koehler, Paul Hartveg, Martina Zügel, Uwe Schumann, Jürgen Michael Steinacker, and Gunnar Treff 


\title{
Carbohydrate Intake in Form of Gel Is Associated With Increased Gastrointestinal Distress but Not With Performance Differences Compared With Liquid Carbohydrate Ingestion During Simulated Long-Distance Triathlon
}

\author{
Mahdi Sareban and David Zügel \\ Division of Sports and Rehabilitation Medicine, University of Ulm \\ Karsten Koehler \\ Department of Nutrition and Health Sciences, University of Nebraska-Lincoln
}

\author{
Paul Hartveg, Martina Zügel, Uwe Schumann, Jürgen Michael Steinacker, and Gunnar Treff \\ Division of Sports and Rehabilitation Medicine, University of Ulm \\ Corresponding author — Mahdi Sareban, m.sareban@salk.at
}

\begin{abstract}
The ingestion of exogenous carbohydrates $(\mathrm{CHO})$ during prolonged endurance exercise, such as long-distance triathlon, is considered beneficial with regard to performance. However, little is known about whether this performance benefit differs among different forms of $\mathrm{CHO}$ administration. To this end, the purpose of our study was to determine the impact of $\mathrm{CHO}$ ingestion from a semisolid source (GEL) on measures of performance and gastrointestinal (GI) comfort compared with $\mathrm{CHO}$ ingestion from a liquid source (LIQ). Nine well-trained triathletes participated in this randomized crossover study. Each participant completed a 60min swim, 180-min bike exercise, and a 60-min all-out run in a laboratory environment under 2 conditions, once while receiving $67.2 \pm 7.2 \mathrm{~g} \cdot \mathrm{h}^{-1}(M \pm S D)$ of $\mathrm{CHO}$ from GEL and once while receiving $67.8 \pm 4.2 \mathrm{~g} \cdot \mathrm{h}^{-1}$ of $\mathrm{CHO}$ from LIQ. The amount of fluid provided was matched among conditions. Respiratory exchange ratio (RER), blood glucose, and lactate as well as Gl discomfort were assessed at regular intervals during the experiment. The distance covered during the final all-out run was not significantly different among participants ingesting GEL $(11.81 \pm 1.38 \mathrm{~km})$ and LIQ $(11.91 \pm 1.53 \mathrm{~km} ; p=.89)$. RER, blood glucose, and lactate did not differ significantly at any time during the experiment. Seven participants reported GI discomfort with GEL, and no athlete reported GI discomfort with LIQ $(p=.016)$. This study suggests that administration of GEL does not alter long-distance triathlon performance when compared with LIQ, but GEL seems to be associated with reduced GI tolerance. Athletes should consider this a potential disadvantage of GEL administration during long-distance triathlon.
\end{abstract}

Keywords: carbohydrate, endurance performance, nutrition

Triathlon is a multisport event that involves three continuous endurance disciplines-swimming, bicycling, and running. Classic long-distance triathlon events last between 4 and $7 \mathrm{hr}$ for the Half-Ironman distance (1.9- km swim, $90-\mathrm{km}$ bike, 21.1-km run) and between 8 and $17 \mathrm{hr}$ for the Ironman distance (3.8-km swim, 180-km bike, 42.2km run).

It is unanimously recommended that athletes ingest exogenous carbohydrates $(\mathrm{CHO})$ during prolonged endurance exercise to maintain adequate $\mathrm{CHO}$ oxidation rates (Jeukendrup, 2011). In particular, during long-distance triathlon the ingestion of exogenous $\mathrm{CHO}$ becomes more important as distance and duration of the event increase (Jeukendrup, 2011). According to current recommendations, athletes should aim to ingest $60-90 \mathrm{~g} \cdot \mathrm{h}^{-1}$ of $\mathrm{CHO}$ in form of multiple absorbable $\mathrm{CHO}$ such as glucose and fructose during events that last longer than 2.5 hr (Jeukendrup, 2011). 
Currently, available guidelines on $\mathrm{CHO}$ consumption during prolonged endurance exercise have mainly been derived from studies that used $\mathrm{CHO}$ from liquid sources (Smith et al., 2010). However, literature data from cyclists (Havemann \& Goedecke, 2008) as well as anecdotal evidence from long-distance triathletes have suggested that many endurance athletes prefer to consume $\mathrm{CHO}$ in a semisolid, highly concentrated form (GEL) during prolonged endurance events such as long-distance triathlon.

It is surprisingly that very little information is available on the impact of $\mathrm{CHO}$ administration in form of GEL on prolonged endurance exercise performance. Pfeiffer et al. (2010) reported no difference in $\mathrm{CHO}$ oxidation when cyclists exercising at $59 \%$ peak oxygen consumption $\left(\mathrm{V}_{\mathrm{O}_{2} \text { peak }}\right)$ for $180 \mathrm{~min}$ were given $108 \mathrm{~g} \cdot \mathrm{h}^{-1}$ of $\mathrm{CHO}$ either in the form of GEL or from a liquid source. Likewise, the administration of GEL was found to be equally effective in maintaining blood glucose and improving performance in cyclists compared with an isocaloric sports drink (Campbell et al., 2008). In contrast, Burke et al. (2005) reported no significant performance benefit of GEL compared with water only during a half-marathon run (Burke et al., 2005). It is noteworthy that several runners using GEL reported gastrointestinal (GI) discomfort, which was found to have a negative impact on half-marathon performance (Burke et al., 2005).

To our knowledge, no study has directly assessed the impact of $\mathrm{CHO}$ administration in the form of GEL on longdistance triathlon performance. Several conditions unique to triathlon may limit athletes' ability to consume $\mathrm{CHO}$ as recommended. Indeed, athletes are usually unable to consume any food or fluid during the swim, and it has been speculated that the change in body position among the three disciplines may impair gastric emptying and increase GI distress (Peters et al., 1993), such that CHO uptake may be limited when compared with running or cycling alone.

Hence, the purpose of our study was to assess the impact of the form of presentation of exogenous $\mathrm{CHO}$ administration on long-distance triathlon performance and to evaluate the incidence of Gl distress. To this end, welltrained triathletes were administered $\mathrm{CHO}$ in the form of GEL or LIQ during a simulated long-distance triathlon in a controlled laboratory environment. On the basis of the available literature, we hypothesized that administration of $\mathrm{CHO}$ in the form of GEL would result in similar outcomes for performance and metabolism but an increased incidence of $\mathrm{Gl}$ distress.

\section{Methods}

\section{Experimental Design}

The study was conducted as a randomized crossover trial to compare the impact of $\mathrm{CHO}$ administration in form of GEL and LIQ on long-distance triathlon performance, metabolic responses, and GI discomfort. On average, the nine participants who completed both trials were age $38.8 \pm$ $10.1 \mathrm{yr}(M \pm S D)$, weighed $79.1 \pm 7.8 \mathrm{~kg}$, and had a $\mathrm{V}_{\mathrm{O}_{2} \text { peak }}$ of $58.6 \pm 6.5 \mathrm{ml} \cdot \mathrm{kg}^{-1} \cdot \mathrm{min}^{-1}$ (Table 1). Each participant completed two simulated long-distance triathlon trials under laboratory conditions. The trial consisted of a $60-\mathrm{min}$ swim at $90 \%$ of each participant's individual $400-\mathrm{m}$ personal best, a 180 -min bike at $90 \%$ of each participant's ventilatory threshold (VT), and a final 60-min all-out run. The distance covered during the 60 -min run served as our primary outcome of interest. This time-based approach was chosen over a classic time-trial approach because we intended to minimize the impact of inadequate pacing during the swim or bike on run performance. In addition, this design allowed us to compare the impact of GEL versus LIQ on metabolic responses and GI distress during the bike and run without having to account for differences in pacing as a potential confounder. In one condition, participants were given $\mathrm{CHO}$ in the form of $\mathrm{GEL}$; in the other condition, participants were given $\mathrm{CHO}$ in form of LIQ. The order of the conditions was at random, and trials were separated by 7 days. The experimental protocol was approved by the ethical review board of the University of Ulm.

\section{Preliminary Testing}

Seven days before the start of the study, participants completed preliminary testing, which consisted of (a) body composition assessment, (b) an incremental exercise test protocol to determine $\mathrm{V}_{\mathrm{O}_{2} \text { peak }}$ and $\mathrm{VT}$, and (c) a 1-hr continuous

Table 1. Physical Characteristics of the Participants Variable

\begin{tabular}{lc}
\hline & Men $(n=9 ; M \pm S D)$ \\
\hline Age (years) & $38.6 \pm 10.7$ \\
Height $(\mathrm{cm})$ & $184.3 \pm 8.0$ \\
Body mass $(\mathrm{kg})$ & $78.5 \pm 8.1$ \\
Body fat $(\%)$ & $9.1 \pm 3.4$ \\
$\mathrm{~V}_{\mathrm{O}_{2} \text { peak }}\left(\mathrm{ml} \cdot \mathrm{kg}^{-1} \cdot \mathrm{min}^{-1}\right)$ & $58.6 \pm 6.3$ \\
Peak power output $(\mathrm{W})$ & $410 \pm 47.6$ \\
Power output at $90 \% \mathrm{VT}(\mathrm{W})$ & $218 \pm 26.5$ \\
Sweat rate at $90 \% \mathrm{VT}\left(\mathrm{L} \cdot \mathrm{min}^{-1}\right)$ & $1.2 \pm 0.2$ \\
\hline $\mathrm{V}_{\mathrm{O}_{2} \text { peak }}=$ peak oxygen consumption; $\mathrm{VT}=$ ventilatory threshold
\end{tabular}


exercise test to approximate sweat rate. Three-point skinfold measurements (Harpenden Skinfold Caliper, West Sussex, United Kingdom) were used to assess body fat percentage. Both the incremental exercise tests and the 1-hr continuous exercise test were conducted on an electromagnetically braked bicycle ergometer (Lode Excalibur Sport, Groningen, The Netherlands). For the incremental exercise test, participants performed unloaded pedaling $(0 \mathrm{~W})$ for $1 \mathrm{~min}$. The load was then increased by $2 \mathrm{~W}$ every $3 \mathrm{~s}$ until participants reached volitional exhaustion (average test length = $12 \pm 1 \mathrm{~min}$ ), which occurred when participants were unable to maintain a cadence of greater than $60 \mathrm{rpm}$ and their respiratory exchange rate (RER) was greater than 1.1. During the incremental test, oxygen uptake was assessed using a computerized mixing chamber metabolic cart (Cortex MetaMax 3X, Leipzig, Germany), and VT was calculated using the $V$-slope method (Beaver et al., 1986). On the same day, participants exercised on the cycle ergometer for $1 \mathrm{hr}$ at $90 \%$ of their individual VT, which was their designated bike workload for the main experiment. Each participant's sweat rate was assessed as the change in nude body weight over the course of this 1-hr test.

\section{Pretest Conditions}

In an effor to minimize the impact of pretest exercise or diet on any of our outcomes, participants had to refrain from strenuous exercise for at least $48 \mathrm{hr}$ before each trial. In addition, participants were instructed to follow a diet of balanced macronutrient composition (> 50\% of energy from $\mathrm{CHO}$, protein intake $>1.4 \mathrm{~g} / \mathrm{kg} / \mathrm{d}$ ) in agreement with current recommendations (Rodriguez et al., 2009) for at least $48 \mathrm{hr}$ before the first trial and were asked to consume a CHO-rich meal no later than $4 \mathrm{hr}$ before the first trial. Participants recorded their diet and physical activity for $48 \mathrm{hr}$ before the first trial. Participants were given a copy of their diet and physical activity logs and were instructed to consume the same diet and conduct the same type and amount of physical activity during the $48 \mathrm{hr}$ before the second trial. Participants were advised to record any deviation from the previously recorded diet or physical activity on their logs.

\section{Experimental Protocol}

Both trials started at the same time of day. On arrival at the laboratory, participants were weighed without clothing (Model 86, Seca, Hamburg, Germany), and the exercise protocol (Figure 1) was initiated. The trial started with a $1-\mathrm{hr}$ swim at a pace equivalent to $90 \%$ of each participant's $400-\mathrm{m}$ personal best. To ensure appropriate pacing during the swim, split times were checked every $100 \mathrm{~m}$ and, in the case of inadequate pacing, participants were prompted to adjust their pace. Swimming was conducted in a chlorinated $25-\mathrm{m}$ indoor pool with a water temperature of $23^{\circ} \mathrm{C}$. The distance covered during each trial was recorded. After the swim, participants were allowed to change and were transferred by car to the laboratory. The transfer time between swim and bike was 19.8 $\pm 2.4 \mathrm{~min}$. After nude body weight was recorded, participants were positioned on an electromagnetically braked bicycle ergometer (Lode Excalibur Sport, Groningen, The Netherlands) and started to bike for $180 \mathrm{~min}$ at a workload corresponding to $90 \%$ of their individual VT.

After completing the 180-min bike, nude body weight was measured again, and participants began to run for $1 \mathrm{hr}$ on a treadmill (Woodway, PPS Med, Weil am Rhein, Germany). The transfer time between bike and run remained less than 4 min in every case. Participants were asked to self-select their pacing during the 1-hr run, but they were strongly encouraged to cover the greatest distance possible. Participants were able to see and manually

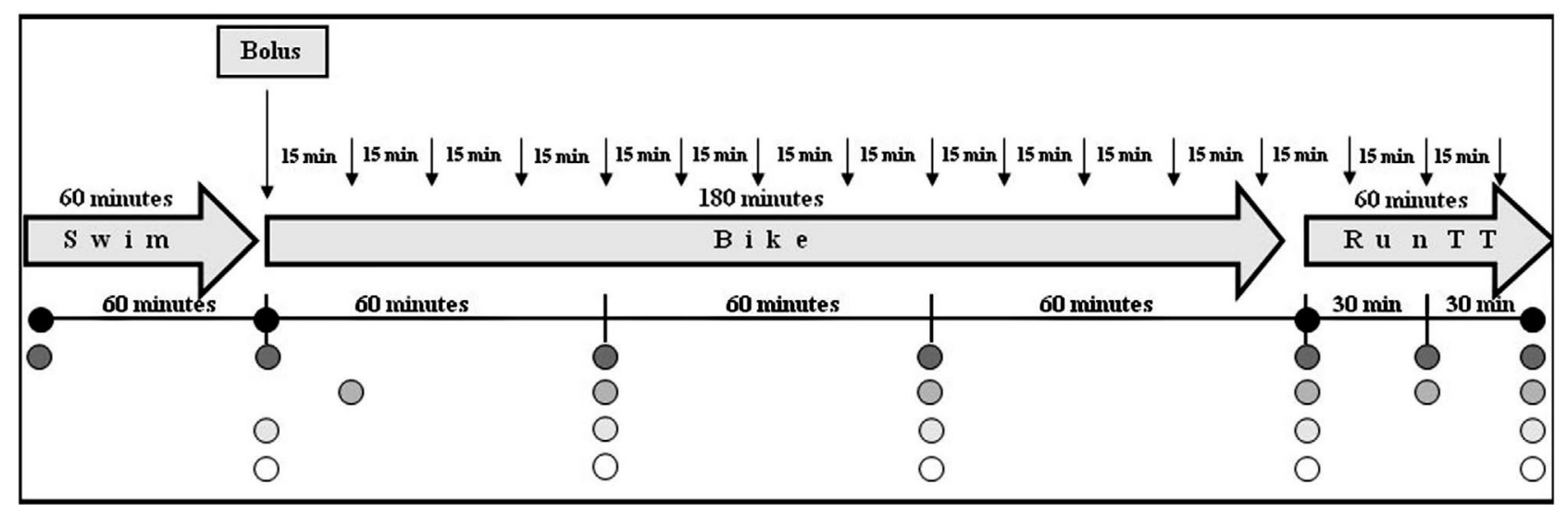

Body weight $\bigcirc$ Lactate/Glucose $\bigcirc$ RER

BORG questionnaire

GI questionnaire

Figure 1. Study design. Arrows indicate ingestion time point of nutrition. Circles indicate time point of data acquisition. Lactate and glucose were measured in capillary blood. RER = respiratory exchange ratio; Run TT = run time trial. 
modify the pace on the control panel of the treadmill, allowing them a continuous self-pacing similar to real-life conditions, where athletes are usually aware of their pace on because of the use of a GPS monitor, distance markers on the course, or both. The distance covered during the run was recorded. On completion of the run, nude body weight was recorded again. The bike and run were conducted in air-conditioned rooms at a temperature of $18^{\circ} \mathrm{C}$.

\section{Carbohydrate Administration}

During both conditions, the target intake of $\mathrm{CHO}$ was $81 \mathrm{~g} \cdot \mathrm{h}^{-1}$ throughout the bike and run. This amount is in agreement with current guidelines for exogenous $\mathrm{CHO}$ administration during prolonged endurance exercise (Jeukendrup, 2011) and represents the dose that is ingested after the consumption of three servings of GEL.

For the GEL condition, we used a commercially available $\mathrm{CHO}$ gel that contains $27 \mathrm{~g}$ of $\mathrm{CHO}$ (maltodextrin, fructose) per serving with a glucose:fructose ratio of 2:1 (Power-Bar, Nestle, Vevey, Switzerland). For the current study, only GEL with vanilla flavor was chosen, and GEL did not contain caffeine as reported by the label. For each participant, the appropriate amount of GEL (three servings per hour) was loaded into a syringe, and participants discharged the syringe into their mouth under supervision. Additional fluid ingested during the GEL condition was bottled mineral water (Aloisius Quelle, Gundelfingen an der Donau, Germany). LIQ was prepared by adding $54 \mathrm{~g}$ of maltodextrin (Lamperts Maltodextrin 19, Berco, Kieve, Germany) and $27 \mathrm{~g}$ of fructose (Fruktosum, Fagron, Barsbüttel, Germany) to $1 \mathrm{~L}$ of bottled mineral water (Aloisius Quelle, Gundelfingen an der Donau, Germany).

Directly after completing the swim, participants ingested an initial bolus of $300 \mathrm{ml}$ of LIQ containing $27 \mathrm{~g}$ of $\mathrm{CHO}$, or 1 serving of GEL in addition to $300 \mathrm{ml}$ of water. During the bike and the following run part, either GEL or LIQ were given in 15-min intervals such that $\mathrm{CHO}$ intake was $81 \mathrm{~g} \cdot \mathrm{h}^{-1}$. To prevent dehydration, participants were provided with additional water (Aloisius Quelle, Gundelfingen an der Donau, Germany) at the same time points. Each participant was provided with the amount of water that matched his sweat rate as determined during preliminary testing. Participants were highly encouraged by staff to drink all fluid provided such that fluid intake was identical during both conditions. Salt was added to LIQ such that sodium intake from LIQ matched sodium intake from GEL $\left(0.6 \mathrm{~g} \cdot \mathrm{h}^{-1}\right)$.

\section{Data Acquisition and Calculations}

Our primary outcomes of interest were the distance covered during the final run as well as RER, blood glucose and lactate concentrations, ratings of perceived exertion (RPE), and measures of $\mathrm{Gl}$ distress. At the beginning of the bike, every 60 min during the bike, and at 30 min into the run as well as at the end of the run, expired gases were collected for 1 min using a Douglas bag. Three samples were drawn from the bag, and oxygen and carbon dioxide concentrations were assessed using photoacoustic spectroscopy (Innocor, Innovision, Odense, Denmark). RER was calculated from the averages of the three measurements. At the beginning of the bike, every 60 min during the bike, and 30 min into the run and at the end of the run, capillary blood samples were collected from the hyperemized earlobe, and hemolyzed samples were assessed for glucose and lactate concentrations (EKF Diagnostics, Biosen C-Line, Cardiff, United Kingdom). RPE was assessed at the beginning of the bike, every 60 min during the bike, and at the beginning and end of the run using the 6-20 Borg scale (Borg, 1974). At the beginning of the bike, every 60 min during the bike, and at the beginning and end of the run, the participants were asked by study staff whether they experienced any form of $\mathrm{Gl}$ distress. In addition, participants completed a questionnaire asking for common Gl symptoms (bloating, flatulencies, urge for defecation, defecation, stomach cramps, pain, diarrhea) after the end of the trial.

\section{Statistical Analysis}

Statistical analysis of this crossover study was conducted as described previously by Wellek and Blettner (2012): To account for carryover effects such as physiological training effects as well as period effects, such as familiarization with the study and laboratory environment, preliminary data analysis based on unpaired $t$ statistics was conducted. To test for differences in treatment effects, a Student's $t$ test for independent samples was used (Wellek \& Blettner, 2012). McNemar's exact test was conducted to compare the incidence of GI distress among conditions. Statistical significance was assumed for $p<.05$. All statistical analyses were performed using SPSS Version 19 for Windows (SPSS, Inc., Chicago, IL).

\section{Results}

\section{Participants}

A total of 10 triathletes were recruited for the study. One participant withdrew from the experiment at the beginning of the run of his second trial because of exhaustion and was subsequently excluded from data analysis.

\section{Pretest Conditions}

Self-reported caloric intake during the 48-hr period before the trials was not significantly different between the two conditions (Table 2). Average $\mathrm{CHO}$ intake during the 48$\mathrm{hr}$ period before the experiments was $5.3 \pm 0.5 \mathrm{~g} \cdot \mathrm{kg}^{-1} \cdot \mathrm{d}^{-1}$ (GEL) and $5.1 \pm 0.4 \mathrm{~g} \cdot \mathrm{kg}^{-1} \cdot \mathrm{d}^{-1}(\mathrm{LIQ} ; p=.73)$. In addition, there were no significant differences in protein and fat intake before the experiment between conditions (Table 2). 
Table 2. Self-Reported Diet During the Period Before the Trials Pretrial Diet

\begin{tabular}{lrrr}
\hline & Gel $(M \pm S D)$ & Liquid $(M \pm S D)$ & $p$ \\
\hline 48 hr before the experiment & & & \\
Caloric intake (kcal/day) & $2,788 . \pm 351$ & $2,608 . \pm 265$ & .339 \\
Carbohydrate intake (g/kg/day) & $5.3 \pm 0.5$ & $5.1 \pm 0.4$ & .727 \\
Protein intake (g/kg/day) & $1.2 \pm 0.3$ & $1.1 \pm 0.3$ & .786 \\
Fat intake (g/kg/day) & $0.9 \pm 0.1$ & $0.8 \pm 0.1$ & 1.000 \\
4 hr before the experiment & & & \\
Caloric intake (kcal) & $1,623 . \pm 306$ & $1,670 . \pm 257$ & .777 \\
Carbohydrate intake (g/kg) & $4.9 \pm 0.4$ & $4.8 \pm 0.4$ & .671 \\
Fiber intake $(\mathrm{g} / \mathrm{kg})$ & $4.8 \pm 3.5$ & $4.9 \pm 3.5$ & .780 \\
Protein intake $(\mathrm{g} / \mathrm{kg})$ & $0.3 \pm 0.1$ & $0.3 \pm 0.1$ & .734 \\
Fat intake $(\mathrm{g} / \mathrm{kg})$ & $0.3 \pm 0.1$ & $0.3 \pm 0.1$ & .687 \\
\hline
\end{tabular}

\section{Swim and Bike Performance}

No significant difference was found in the distance covered during the 1 -hr swim between the conditions (3,473.1 $\pm 311.4 \mathrm{~m}$ [GEL] vs. 3,534.4 $\pm 314.1 \mathrm{~m}$ [LIQ]; $p=.69$ ). Participants started cycling at an average load of $204.1 \pm 27.6$ W. For 4 participants (GEL, $n=3$; LIQ $n=1$ ), load was reduced by $22 \pm 7.7 \mathrm{~W}$ after $66.3 \pm 46.8$ min during the first trial to avoid preemptive exhaustion and to allow the participants to complete the experiment. During the second trial, load was reduced by the same degree at identical time points to match load during both bike conditions.

\section{Running Performance}

On average, participants covered a distance of $11.81 \mathrm{~km}$ during the $1-\mathrm{hr}$ run in the GEL condition and $11.91 \mathrm{~km}$ during the LIQ condition, which did not significantly differ from each other $(p=.88)$.

\section{Fluid and Carbohydrate Intake During the Experiment}

There was a trend indicating that total fluid intake over the course of the experiment was lower in the GEL condition $\left(3.9 \pm 0.54 \mathrm{~L} / 0.78 \pm 0.11 \mathrm{~L} \cdot \mathrm{h}^{-1}\right)$ than in the LIQ condition ( $\left.4.2 \pm 0.25 \mathrm{~L} / 0.84 \pm 0.5 \mathrm{~L} \cdot \mathrm{h}^{-1} ; p=.10\right)$. Body mass decreased during both conditions, but the reduction in body mass was not significantly different between the two conditions (1.6 $\pm 0.7 \%$ [GEL] vs. $1.9 \pm 0.5 \%[\mathrm{LIQ}] ; p=.17)$. Total $\mathrm{CHO}$ intake was $336 \pm 36 \mathrm{~g}\left(67.2 \pm 7.2 \mathrm{~g} \cdot \mathrm{h}^{-1}\right)$ in the GEL condition and $339 \pm 21 \mathrm{~g}\left(67.8 \pm 4.2 \mathrm{~g} \cdot \mathrm{h}^{-1}\right)$ in the LIQ condition and did not significantly differ between conditions $(p=.85)$. Figure 2 depicts the $\mathrm{CHO}$ intake during the experiment.

\section{Glucose and Lactate}

Blood glucose remained stable throughout the experiment in both conditions (Figure 3) and did not drop below

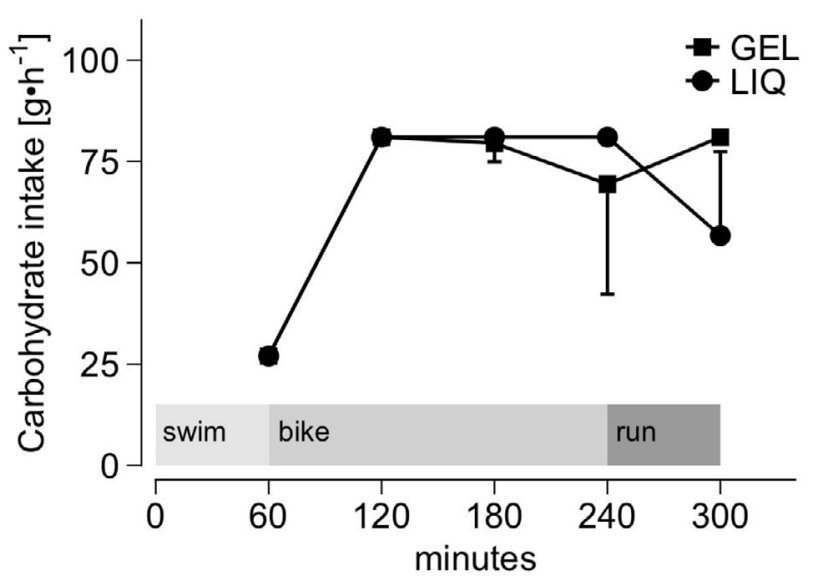

Figure 2. Carbohydrate $(\mathrm{CHO})$ intake during the experiment. Values are arithmetic $M \pm S D$. GEL = carbohydrate ingestion from semisolid source; LIQ = carbohydrate ingestion from liquid source.

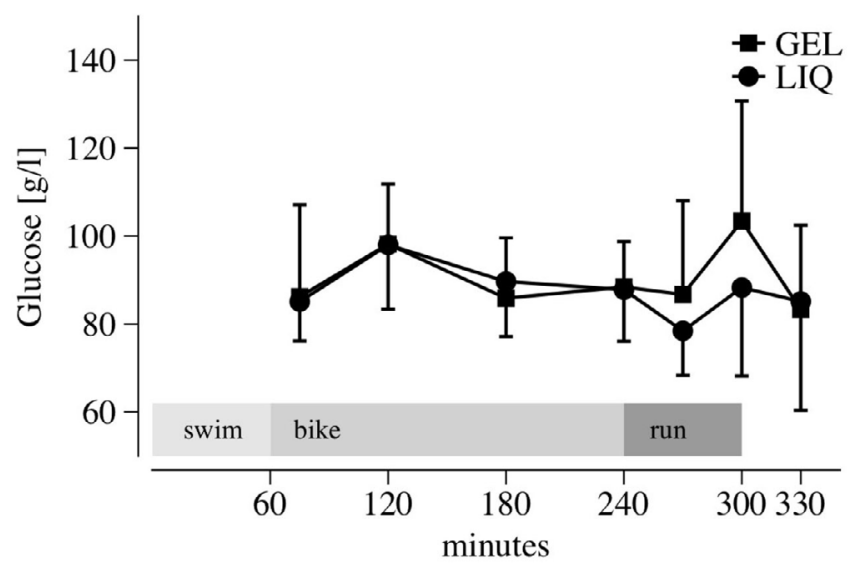

Figure 3. Blood glucose during the experiment. Values are arithmetic $M \pm S D$. GEL = carbohydrate ingestion from semisolid source; LIQ = carbohydrate ingestion from liquid source. 
$4 \mathrm{mmol} \cdot \mathrm{L}^{-1}$ at any time during the experiment. No statistically significant difference was found in blood glucose between conditions at any time during the experiment. At the end of the run, glucose was $5.7 \pm 1.5 \mathrm{mmol} \cdot \mathrm{L}^{-1}$ in the GEL condition versus $4.4 \pm 1.0 \mathrm{mmol} \cdot \mathrm{L}^{-1}$ in the LIQ condition $(p=.22)$. Lactate increased after the bike part in both conditions (Figure 4), but no significant differences were found in lactate between conditions at any time point across the experiment. Lactate concentrations at the end of the run were $2.3 \pm 0.9 \mathrm{mmol} \cdot \mathrm{L}^{-1}$ in the GEL condition and $2.1 \pm 1.1 \mathrm{mmol} \cdot \mathrm{L}^{-1}$ in the LIQ condition $(p=.70)$.

\section{Respiratory Exchange Ratio}

RER decreased continuously during the bike and run, and no significant differences were found in RER between the conditions at any time during the experiment. RER at the end of the run was $0.88 \pm 0.21$ in the GEL condition and $0.88 \pm 0.37$ in the LIQ condition $(p=.78)$.

\section{Rating of Perceived Exertion}

RPE did not differ significantly between GEL and LIQ conditions during bike and run at any time point. Likewise,

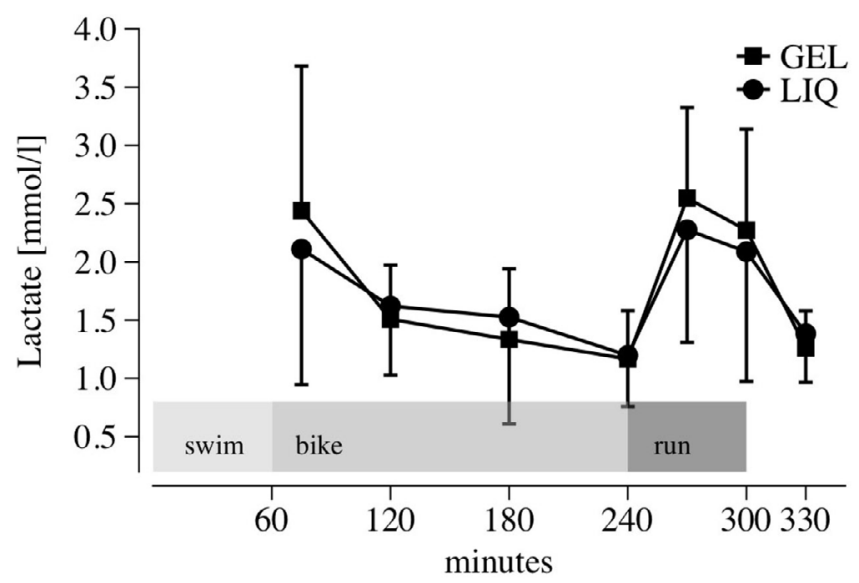

Figure 4. Blood lactate concentration during the experiment. Values are arithmetic $M \pm S D$. GEL = carbohydrate ingestion from semisolid source; LIQ = carbohydrate ingestion from liquid source.
RPE at the end of the run was not significantly different between conditions (GEL: $16.2 \pm 1.9$; LIQ: $16.3 \pm 1.3$; $p$ $=.85)$.

\section{Gastrointestinal Distress}

Seven of the 9 participants reported Gl symptoms (Table 3 ) in the GEL condition. One participant had to defecate between the bike and the run. No participant reported GI symptoms in the LIQ condition. The difference in the incidence of $\mathrm{Gl}$ distress between conditions was significant $(p=.016)$.

\section{Discussion}

The purpose of the current study was to assess the impact of exogenous $\mathrm{CHO}$ administration in form of GEL versus LIQ on performance, metabolic measures, and GI distress during a 5-hr triathlon in a laboratory environment. Our primary finding was that performance was not affected by the ingestion of $\mathrm{CHO}$ in the form of GEL compared with $\mathrm{CHO}$ in the form of LIQ. However, we demonstrated that the use of GEL was associated with a significantly higher incidence of $\mathrm{GI}$ distress than was the use of $\mathrm{LIQ}$.

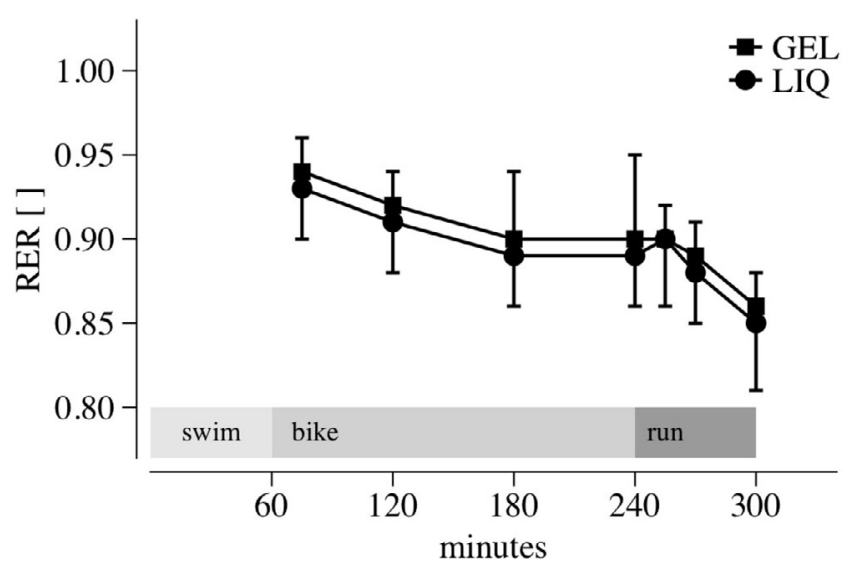

Figure 5. Respiratory exchange ratio (RER) during the experiment. Values are arithmetic $M \pm S D$. GEL = carbohydrate ingestion from semisolid source; $L I Q$ = carbohydrate ingestion from liquid source.

Table 3. Symptoms of Gastrointestinal Distress During the Experiment

\begin{tabular}{lcc}
\hline Symptom & Gel & Liquid \\
\hline Bloating & 5 & 0 \\
Bloating + urge for defecation & 1 & 0 \\
Bloating + defecation & 1 & 0 \\
Total & 7 & 0 \\
\hline
\end{tabular}

$N=9 . p=.016$. Values express number of participants with corresponding gastrointestinal symptoms. 
Our results obtained during prolonged exercise (300 min) complement previous results during shorter exercise durations, according to which $\mathrm{CHO}$ administration in form of GEL was not associated with differences in performance when compared with $\mathrm{CHO}$ administration in form of $\mathrm{LIQ}$. Campbell et al. (2008) reported that $\mathrm{CHO}$ administration in form of GEL resulted in a $2.8 \%$ improvement in $10-\mathrm{km}$ cycling time trial performance compared with water, but no performance benefit was observed when compared with administration of the same amount of $\mathrm{CHO}$ in form of LIQ or sport beans (Campbell et al., 2008).

In the current study, metabolic measures of blood glucose and RER did not suggest a difference in $\mathrm{CHO}$ uptake or oxidation between conditions. This observation is in agreement with a previous experiment with cyclists, in whom measures of $\mathrm{CHO}$ oxidation were similar between GEL and LIQ during 180 min of stationary cycling at $58 \%$ of their maximal oxygen uptake $\left(\mathrm{V}_{\mathrm{O}_{2} \text { maxi }}\right.$ Pfeiffer et al., 2010).

Another important finding of our study was that the majority of the participants in the GEL condition reported symptoms of GI distress, whereas LIQ appeared to be tolerated well by every participant. This result is in agreement with a previous report of a higher prevalence of $\mathrm{Gl}$ distress in half-marathon runners after gel administration compared with the use of water only (Burke et al., 2005). Symptoms reported in the current study included flatulencies, bloating, and the urge to defecate, which are common Gl complaints in endurance sports (Brouns et al., 1987). A prevalence of $\mathrm{Gl}$ distress of $3 \%-23 \%$ has been reported in running (Pfeiffer et al., 2009), and Gl distress presents one of the leading causes of dropout in long-distance triathlon (Jeukendrup et al., 2000).

$\mathrm{Gl}$ distress is more likely to occur with the ingestion of concentrated $\mathrm{CHO}$ solutions (Rehrer et al., 1992) such as gel products as the result of an osmotically driven influx of water into the gut. In this study, $\mathrm{CHO}$ uptake during the run was higher in the GEL condition $\left(81 \pm 0 \mathrm{~g}^{\circ} \mathrm{h}^{-1}\right) \mathrm{com}$ pared with the LIQ condition $\left(54 \pm 21 \mathrm{~g} \cdot \mathrm{h}^{-1}\right)$. In addition, total fluid intake was slightly lower in the GEL condition, leading to a higher concentration of $\mathrm{CHO}$ during that condition. The slightly higher $\mathrm{CHO}$ intake in conjunction with the slightly lower fluid intake may-at least in part-explain the higher Gl distress observed in our study participants during the run and underlines the recommendation to consume a sufficient amount of water after gel consumption. A noteworthy finding was that 2 participants refused to consume the full amount of $\mathrm{CHO}$ provided in the GEL condition because of GI discomfort experienced during the bike part, indicating that some athletes experience $\mathrm{Gl}$ distress even when consuming adequate amounts of water. Other diet-related causes of GI distress that have been reported for long-distance triathlon, such as a high fiber, fat, or protein content (Rehrer et al., 1992), can be ruled out because macronutrient intake was limited to the ingestion of $\mathrm{CHO}$ during the current study.
All participants experienced difficulties in consuming the whole amount of fluid during the run (explaining why $\mathrm{CHO}$ uptake was lower in the LIQ condition), but average fluid loss was less than $2 \%$ of the body mass, which is in agreement with current recommendations of the American College of Sports Medicine (Sawka et al., 2007).

The ability to maintain $\mathrm{CHO}$ intake at high levels may become more relevant during the final run of an Ironmandistance triathlon, when maintenance of exogenous $\mathrm{CHO}$ intake is essential to prevent fatigue and a consequent race dropout (Jeukendrup et al., 2000). Even though our 5-hr laboratory protocol did not show performance differences, the observed lower $\mathrm{CHO}$ intake during the run in the LIQ condition might limit performance during the final Ironman marathon after more than $5 \mathrm{hr}$ of swimming and cycling. In this case, the use of an easily carried and consumed gel might be beneficial as long as hydration is assured. Consequently, athletes are required to carefully balance the potential risk of $\mathrm{Gl}$ discomfort and the risk of $\mathrm{CHO}$ depletion and fatigue because a high $\mathrm{CHO}$ intake is associated not only with GI distress but also with performance benefits (Pfeiffer et al., 2012).

Another factor that athletes should consider is the financial cost associated with $\mathrm{CHO}$ administration during long-distance triathlon. The commercially available GEL product used in the current study was approximately 6 times more expensive than the ingredients used for preparing LIQ. Because the general recommendation is to test diet strategies during training, this difference in cost may become relevant particularly for nonprofessional athletes.

\section{Limitations}

This study used a newly developed long-distance triathlon simulation protocol, which was designed to mimic the multidisciplinary character of triathlon competition but still allow for standardized assessments under laboratory conditions. However, the duration of the bike (180 $\mathrm{min}$ ) and run (60 $\mathrm{min}$ ) were shorter than these sections in an Ironmandistance triathlon. Thus, it is possible that a longer bike or run could elicit performance effects of one form of $\mathrm{CHO}$ administration over another. However, in particular a longer run could have led to more conservative pacing, thus attenuating potential benefits of a potentially higher $\mathrm{CHO}$ availability from one form of administration than from another.

Intensity during swim and bike was clamped to minimize the risk of premature dropout due to overpacing and to allow for metabolic measurements to be conducted at steady-state exercise and following standardization of $\mathrm{CHO}$ intake. We used the distance covered during final 1-hr run as a surrogate for overall triathlon performance. Although this design might discriminate against triathletes who are strong cyclists but poor or mediocre runners, a constant power output and the consumption of high amounts of $\mathrm{CHO}$ on the bike were the main criteria of overall long-distance triathlon success (Wu et al., 2014). 
We allowed our participants to see and manually modify the pace of the treadmill during the final all-out run to mimic real-life conditions. This strategy might have led the participants to match the pace of the first trial despite their perceived exertion and thus reduced the chances of seeing effects. However, neither running performance nor related physiological variables such as heart rate, lactate, and RPE changed, indicating that participants were not just sticking to a chosen speed despite sensory feedback.

Another limitation is the transfer time between swim and bike of $19.8 \pm 2.4 \mathrm{~min}$, which is approximately 5 times longer than in real-life long-distance triathlons. The longer transition was unavoidable to allow for the car transfer from the local pool to the laboratory.

The current experiment was neither blinded nor placebo controlled, which was deemed not feasible because of differences in texture and form of presentation between LIQ and GEL. In addition, we did not use a control group that did not administer $\mathrm{CHO}$ in the current study. Because it is unanimously accepted that $\mathrm{CHO}$ administration is associated with a performance benefit during prolonged endurance exercise (Jeukendrup, 2011), we decided against adding additional non- $\mathrm{CHO}$ control conditions, such as $\mathrm{CHO}$-free $\mathrm{GEL}$ or $\mathrm{CHO}$-free $\mathrm{LIQ}$, in efforts to minimize participant burden.

\section{Conclusion}

This study demonstrates that the administration of $\mathrm{CHO}$ in form of a gel product is not associated with differences in performance during a simulated long-distance triathlon compared with a liquid $\mathrm{CHO}$ solution prepared from maltodextrin and fructose. In addition, our study confirms previous findings that the use of GEL is associated with an increased risk of $\mathrm{Gl}$ distress. Athletes and supporting staff should carefully consider the potential advantages and disadvantages of different forms of $\mathrm{CHO}$ administration during long-distance triathlon.

Acknowledgments - This study was not supported by external funding. There is no conflict of interest to report. The authors thank all of the participants for their enthusiasm and the time they dedicated to the study.

\section{References}

Beaver, W.L., Wasserman, K., \& Whipp, B.J. (1986). A new method for detecting anaerobic threshold by gas exchange. Journal of Applied Physiology, 60, 2020-2027.

Borg, G.A. (1974). Perceived exertion. Exercise and Sport Sciences Reviews, 2, 131-153.

Brouns, F., Saris, W.H., \& Rehrer, N.J. (1987). Abdominal complaints and gastrointestinal function during long-lasting exercise. International Journal of
Sports Medicine, 8, 175-189. doi:10.1055/s-20081025653

Burke, L.M., Wood, C., Pyne, D.B., Telford, D.R., \& Saunders, P.U. (2005). Effect of carbohydrate intake on half-marathon performance of well-trained runners. International Journal of Sport Nutrition and Exercise Metabolism, 15, 573-589.

Campbell, C., Prince, D., Braun, M., Applegate, E., \& Casazza, G.A. (2008). Carbohydrate-supplement form and exercise performance. International Journal of Sport Nutrition and Exercise Metabolism, 18, 179-190.

Havemann, L., \& Goedecke, J.H. (2008). Nutritional practices of male cyclists before and during an ultraendurance event. International Journal of Sport Nutrition and Exercise Metabolism, 18, 551-566.

Jeukendrup, A.E. (2011). Nutrition for endurance sports: Marathon, triathlon, and road cycling. Journal of Sports Sciences, 29(Suppl. 1), S91-S99. doi:10.1080/0264041 4.2011 .610348

Jeukendrup, A.E., Vet-Joop, K., Sturk, A., Stegen, J.H., Senden, J., Saris, W.H., \& Wagenmakers, A.J. (2000). Relationship between gastro-intestinal complaints and endotoxaemia, cytokine release and the acute-phase reaction during and after a long-distance triathlon in highly trained men. Clinical Science, 98, 47-55. doi:10.1042/cs0980047

Peters, H.P., van Schelven, F.W., Verstappen, P.A., de Boer, R.W., Bol, E., Erich, W.B., . . de Vries, W.R. (1993). Gastrointestinal problems as a function of carbohydrate supplements and mode of exercise. Medicine and Science in Sports and Exercise, 25, 1211-1224. doi:10.1249/00005768-199311000-00003

Pfeiffer, B., Cotterill, A., Grathwohl, D., Stellingwerff, T., \& Jeukendrup, A.E. (2009). The effect of carbohydrate gels on gastrointestinal tolerance during a $16-\mathrm{km}$ run. International Journal of Sport Nutrition and Exercise Metabolism, 19, 485-503.

Pfeiffer, B., Stellingwerff, T., Hodgson, A.B., Randell, R., Pöttgen, K., Res, P., \& Jeukendrup, A.E. (2012). Nutritional intake and gastrointestinal problems during competitive endurance events. Medicine and Science in Sports and Exercise, 44, 344-351. doi:10.1249/ MSS.0b013e31822dc809

Pfeiffer, B., Stellingwerff, T., Zaltas, E., \& Jeukendrup, A.E. (2010). CHO oxidation from a $\mathrm{CHO}$ gel compared with a drink during exercise. Medicine and Science in Sports and Exercise, 42, 2038-2045. doi:10.1249/ MSS.0b013e3181e0efe6

Rehrer, N.J., van Kemenade, M., Meester, W., Brouns, F., \& Saris, W.H. (1992). Gastrointestinal complaints in relation to dietary intake in triathletes. International Journal of Sport Nutrition, 2, 48-59.

Rodriguez, N.R., Di Marco, N.M., \& Langley, S. (2009). American College of Sports Medicine position stand: Nutrition and athletic performance. Medicine and Science in Sports and Exercise, 41, 709-731. 
Sawka, M.N., Burke, L.M., Eichner, E.R., Maughan, R.J., Montain, S.J., \& Stachenfeld, N.S. (2007). American College of Sports Medicine position stand: Exercise and fluid replacement. Medicine and Science in Sports and Exercise, 39, 377-390.

Smith, J.W., Zachwieja, J.J., Peronnet, F., Passe, D.H., Massicotte, D., Lavoie, C., \& Pascoe, D.D. (2010). Fuel selection and cycling endurance performance with ingestion of [13C]glucose: Evidence for a carbohydrate dose response. Journal of Applied Physiology, 108, 1520-1529.

Wu, S.S., Peiffer, J.J., Brisswalter, J., Nosaka, K., \& Abbiss, C.R. (2014). Factors influencing pacing in triathlon. Open Access Journal of Sports Medicine, 5, 223-234.

Wellek, S., \& Blettner, M. (2012). On the proper use of the crossover design in clinical trials: Part 18 of a series on evaluation of scientific publications. Deutsches Ärzteblatt International, 109, 276-281. 